\title{
The Relationship Between Length of Hemodialysis Period, Diabetic Comorbidity, and Adequacy of Hemodialysis to the Changes of Sga Score on Hemodialysis Patients in Rsij Cp Hospital
}

\author{
Sunarti ${ }^{1}$ and Siti Arifah Pujonarti ${ }^{2}$ \\ ${ }^{1}$ Dietitien at RSIJ CP Hospital, Indonesia \\ ${ }^{2}$ Nutrition Department, Faculty of Public Health, University of Indonesia
}

\section{Abstract}

CKD (Chronic Kidney Disease) and other chronic diseases were potential to prevalence of hospital malnutrition and caused financial burden. In CKD stage 5 performed dialysis, malnutrition increased with hypercatabolic related to disease progression or nutritional disorders during dialysis, and psychosocial issues such as depression and economic

Corresponding Author:

Sunarti

Received: 21 December 2018

Accepted: 23 January 2019

Published: 28 February 2019

Publishing services provided by

Knowledge E

(c) Sunarti and Siti Arifah

Pujonarti. This article is

distributed under the terms of

the Creative Commons

Attribution License, which

permits unrestricted use and

redistribution provided that the

original author and source are

credited.

Selection and Peer-review under the responsibility of the 3rd IMOPH \& the 1st YSSOPH Conference Committee. factors. Inadequacy of dialysis treatment might be an important cause of malnutrition. This study aimed to describe association between length of hemodialysis period, diabetic comorbidity, and adequacy of hemodialysis to the changes of SGA (Subjective Global Asessment) score on HD patients at RSIJ CP hospital on February and July 2017. This was a cohort retrospective study used secondary data from medical record and nutritional status screening report. Data from a total of 90 maintenance hemodialysis patients participated on this study. The inclusion criteria were being on HD for at least three month, upper 15th years old, having complete data such as social demographic, date of HD initiating, medical diagnosis, the $\mathrm{Qb}$ rate, dry body weight, and HD duration of eight-time HD on last observasion, SGA score and BMI (Body Mass Index) on two period (February and July 2017). There was no significant differences between the changes of SGA score to demographic variables, except to marietal status ( $p=0.003$ ). There was no significant differences between the changes of SGA score to the length of HD period ( $p=0.527)$, and to adequacy of hemodialysis $(p=0.484)$. exception to Diabetic comorbidity $(p=0.043$ ). There was $73.7 \%$ of patients with HD period $\geq 2$ years had no improvement of SGA score. There was a younger tendency in increased SGA score group (worsening) than in decreased SGA score group $(48.8+15.4$ vs $55.9+10.4$ years), meanwhile $64.4 \%$ of patients were maintenance HD patients under 2 years periode. Increased prevalence of HD patients with worsening SGA score in younger patients which period of $H D<2$ years was sign for better monitoring program and nutrition intervention. Further studies needed for correlation and regression to get dominant variables as determinant of nutritional status changes so appropriate nutritional intervention program could be delivered to improve quality of life of HD patients.

Keywords: SGA score, length of hemodialysis period, diabetic comorbidity, adequacy S OPEN ACCESS 


\section{Introduction}

A systematic review of 26 studies (2003 - 2006) showed that prevalence of Chronic Kidney Diseases (CKD) in the USA was 7.2\% in persons aged 30 years or older, whereas in population aged 64 years or older, prevalence of CKD varied from $23.4 \%$ to $35.8 \%$ (Zhang and Rothenbacher, 2008). Data from CIHI (Canadian Institute for Health Information) in 2010 indicated that CKD prevalence in Canada increased by 20\% from 1999 to 2008 (5,431 patients in 2008), with 76\% - 78\% of them had received initial HD treatment. Early treatment seemed to show a good response at the population level that the annual rate growth in the prevalence of CKD decreased from 4.5\% (for HD 6.1\%) in 2000 to $-1.4 \%$ (for HD -2.3\%) in 2008 (Fortin, C. M. et al., 2010).

The average incidence figure was reported to be around 200 cases per million per year in many countries. In the USA, Taiwan, and some regions in Mexico, the number approached 400 cases per million and had risen faster in the older population. Dialysis is the main method of applied for CKD in most countries with an average survival of 3-5 years in the USA, prevalence nears to 1800 cases per million. In Japan and Taiwan, high survival rate translates to high prevalence approach 2400 cases per million (Levey and Coresh, 2012). Indonesian Renal Registry (2012) reported that CKD incidents with the HD treatment increased by $294,3 \%$ (from 4.977 patients in 2007 to 19.621 patients in 2012).

Also, National Health Insurance (JKN) data in 2015 revealed that 23.9\% of the cost of health services was spent finance catastrophic diseases and CKD disease ranks second after heart disease. Similarly, the number of CKD cases had been increasing in the United States, and with increasing prevalence, it was predicted that by 2010 , there were almost 700,000 dialysis patients in the United States, costing about US\$30 million a year for their dialysis treatment. Treatment of such an ever-increasing burden of end-stage kidney failure could not be afforded, even in the wealthiest of countries (Atkins, 2005).

In addition to the HD treatment cost itself, there is a hidden cost associated with cases of CKD on HD treatments, among which is a cost associated with malnutrition. Assessment for the hospital financial cost caused by undiagnosed or undocumented cases of malnutrition has been done in some studies, by using SGA (Subjective Global Assessment) as an instrument to assess the risk of malnutrition. With this technique, it was found that in Brisbane financial loss was AUD 1,677,235 annually, while in Melbourne it was estimated that the deficit to the hospital in reimbursements was of AUD 1,850,540 annually. In Germany, the annual financial shortfall is found to be $€ 35,280$. Similarly, the USA reported a loss of more than USD 86,000 after conducting a retrospective audit of patient medical charts [6].

In CKD stage 5 patient who underwent dialysis, their risk of malnutrition increased due to the hyper-catabolic state associated with disease progression or nutritional disorders during dialysis, and further compound by psychosocial issues such as depression and economic factors. Nutritional problems in adult patients with stage 5 CKD on dialysis could be classified into three categories: protein-energy wasting (PEW), obesity and diabetes. PEW in dialysis is related to inadequate food intake, abnormal nutrient metabolism (primarily in amino acids metabolism), residual renal function and dialysis dose (Heng and Cano, 2009). 
Some studies reported a positive correlation between the adequacy of hemodialysis and subjective global assessment of nutritional status. The inadequacy of dialysis treatment might be an important cause of malnutrition (Locatelli et al., 2002). Kidney Disease Outcomes Quality Initiative (KDOQI) Guideline for Hemodialysis Adequacy (2015) recommended a single target pool Kt/V (spKt/V) of 1.8 per hemodialysis session for patients treated thrice weekly, with a minimum delivered spKt/V of 1.2 and the Urea Reduction Ratio (URR) minimum 65\%. Good general and nutritional condition were some of the clinical criteria of adequate dialysis (N.K. Man, et al, 1995). Urea reduction was found to be a predictor factor for patient's appetite.

\section{Materials dan Methods}

The study employed a cohort retrospective design and descriptive, analytical study, utilizing secondary data from the medical record and nutritional status screening report. The inclusion criteria were 1) patients on HD at the HD Outpatient Unit in Rumah Sakit Islam Jakarta Cempaka Putih (RSIJ CP) for at least three months, 2) aged above 15th years, 3) complete data could be found in their medical records for their: social demographic (age, gender, marital status, employee status, and education), date of HD initiating, medical diagnosis, the Qb (Quick of blood) rate, dry body weight, SGA score and BMI (Body Mass Index), and 4) having completed eight HD treatments between the selected time frame (February and July period in 2017).

A total of 136 CKD patients on maintenance hemodialysis for at least three months were selected from the Hemodialysis Outpatient Unit at RSIJ CP during February and July 2017. From theses, patients who have nutritional assessment between February 2017 and July 2017 are the population study. Patients were excluded if passed away $(n=3)$, couldn't be measured for SGA and BMl or with missing data $(n=40)$ and were HD transfer to another HD unit $(n=3)$. Thus, data from 90 patients were collected in the study. SGA and BMI data were collected from nutritional status screening report in Nutrition Department of RSIJ CP Hospital. The date of HD initiating, medical diagnosis to assess the presence of Diabetic comorbidity, the $Q b$ rate, dry body weight and HD duration of eight-time HD on July 2017 were collected from medical records of each maintenance hemodialysis patient. Descriptive and analytical statistics were carried out to analyze the data.

\section{Results}

Patients characteristic from demographic data are shown in Table 1. The study population had a lower proportion of male patients (48.89\%); a stark difference from other studies which usually have a higher proportion of male patients. The subjects had a mean age of $52.17 \pm 12.6$ years ( $\mathrm{Cl} 95 \%, 49.53-54.81)$, the major education of patients was high school (51.65\%), 85.56\% of patients had married, and $58.89 \%$ was unemployed. Based on HD history, $57.78 \%$ of patients had a length of HD under two years and $73.33 \%$ of patients without Diabetic comorbidity. 
TABLE 1: Patients Characteristic.

Characteristic
Age (years)
Adequacy HD (Kt/V)
Gender, Male
Education, Elementary
Marital Status, Unmarried
Employee Status,
Unemployed
Length oh HD, $\geq 2$ years
Comorbidities, Diabetes
BMI Changes, Decrease
SGA score Changes,
Unchanged
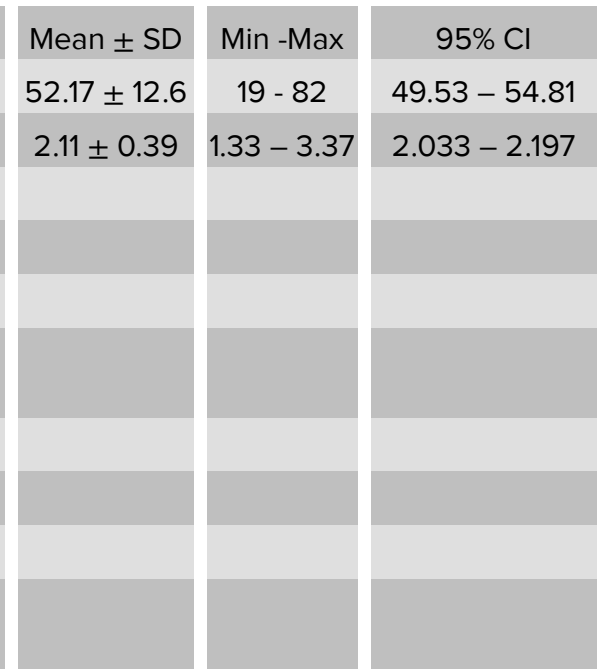

\begin{tabular}{|c|}
\hline$n$ \\
\hline 90 \\
87 \\
44 \\
\hline 25 \\
\hline 7 \\
\hline 53 \\
\hline 38 \\
\hline 24 \\
\hline 47 \\
\hline 68 \\
\hline
\end{tabular}

\begin{tabular}{|c|}
\hline$\%$ \\
\hline 48.89 \\
\hline 27.47 \\
\hline 7.78 \\
\hline 58.89 \\
\hline 42.22 \\
\hline 26.67 \\
\hline 52.22 \\
\hline 74.44 \\
\hline
\end{tabular}

Comparison of BMI on two periods with T-test was resulting in no significant differences of BMI on first period (February) and the second period ( July) with p-value $=0.073$, but the mean of BMI on the first period was still higher than the second period $(23,4+$ 3.7 vs. $22.8 \pm 3.30$ ). Similarly, differences mean of SGA score on the first period and the second period had no significant ( $p$-value $=0.535$ ). Based on One Way ANOVA test to the difference mean of age, there was no significant difference $(p=0.415)$ in all three groups of SGA score changes. The observation period of 132 days in this study and the number of samples might not be able to show significant change. It seemed to look like HEMO Study which involved 893 maintenance HD patients had no significant in the difference of BMI and SGA score after three years of observation. (Rocco et al., 2004).

Statistical test with chi-square showed no significant differences of SGA score changes to gender groups ( $p$-value $=0.734)$, either to the level of education $(p=0.736)$ and to employee status too ( $\mathrm{p}$-value 0.951). It was only to marital status which showed a significant difference $(p=0.003)$. We found 61 patients $(79.2 \%)$ with unchanged SGA score who had married and five patients (71.4\%) with increasing SGA score (worsening) from the unmarried group.

Again, there was no significant differences of SGA score changes to the length of HD period $<2$ years and $\geq 2$ years $(p=0.527)$, to three groups of BMl changes $(p=0.918)$, and to adequacy of hemodialysis with $p$-value 0.484 but there was significant differences of SGA score changes to Diabetic comorbidity $(p=0.043)$. The results were as showed at Table 2. 
TABLE 2: Statistical Tests of Association SGA Score Changes With All Independent Variables.

\begin{tabular}{|c|c|c|c|c|c|c|c|c|c|c|}
\hline \multicolumn{2}{|c|}{ Variables } & \multicolumn{6}{|c|}{ SGA Score Changes } & \multicolumn{2}{|c|}{ Total } & \multirow[t]{3}{*}{$p$-value* } \\
\hline & & \multicolumn{2}{|c|}{ Decreased } & \multicolumn{2}{|c|}{ Unchanged } & \multicolumn{2}{|c|}{ Increased } & \multirow[b]{2}{*}{$\mathrm{n}$} & \multirow[b]{2}{*}{$\%$} & \\
\hline & & $\mathrm{n}$ & $\%$ & $\mathrm{n}$ & $\%$ & $n$ & $\%$ & & & \\
\hline \multirow[t]{3}{*}{1} & Age (years) & & & & & & & & & 0.415 \\
\hline & Mean & \multicolumn{2}{|c|}{55.9} & \multicolumn{2}{|c|}{52.0} & \multicolumn{2}{|c|}{48.8} & & & \\
\hline & SD & \multicolumn{2}{|c|}{10.4} & \multicolumn{2}{|c|}{12.3} & \multicolumn{2}{|c|}{15.4} & & & \\
\hline \multirow[t]{4}{*}{2} & Gender & & & & & & & & & 0.734 \\
\hline & Female & 5 & 10.9 & 33 & 71.7 & 8 & 17.4 & 46 & 100 & \\
\hline & Male & 5 & 11.4 & 34 & 77.3 & 5 & 11.4 & 44 & 100 & \\
\hline & Total & 10 & 11.1 & 67 & 74.4 & 13 & 14.4 & 90 & 100 & \\
\hline \multirow[t]{5}{*}{3} & Education & & & & & & & & & 0.736 \\
\hline & Elementary & 1 & 4.0 & 20 & 80.0 & 4 & 16.0 & 25 & 100 & \\
\hline & High School & 7 & 14.9 & 33 & 70.2 & 7 & 14.9 & 47 & 100 & \\
\hline & College & 2 & 11.1 & 14 & 77.8 & 2 & 11.1 & 18 & 100 & \\
\hline & Total & 10 & 11.1 & 67 & 74.4 & 13 & 14.4 & 90 & 100 & \\
\hline \multirow[t]{5}{*}{4} & Marital Status & & & & & & & & & 0.003 \\
\hline & Unmarried & 0 & 0.0 & 2 & 28.6 & 5 & 71.4 & 7 & 100 & \\
\hline & Married & 9 & 11.7 & 61 & 79.2 & 7 & 9.1 & 77 & 100 & \\
\hline & Widow/Widower & 1 & 16.7 & 4 & 66.7 & 1 & 16.7 & 6 & 100 & \\
\hline & Total & 10 & 11.0 & 67 & 74.4 & 13 & 14.4 & 90 & 100 & \\
\hline \multirow[t]{5}{*}{5} & Employee Status & & & & & & & & & \\
\hline & Unemployee & 6 & 11.3 & 38 & 71.7 & 9 & 17 & 53 & 100 & 0.951 \\
\hline & Student & 0 & 0.0 & 3 & 100.0 & 0 & 0.0 & 3 & 100 & \\
\hline & Employee & 4 & 11.4 & 26 & 77.1 & 4 & 11.4 & 34 & 100 & \\
\hline & Total & 10 & 11.1 & 67 & 74.4 & 13 & 14.4 & 90 & 100 & \\
\hline \multirow[t]{4}{*}{6} & Length of HD Period & & & & & & & & & \\
\hline & $<2$ years & 7 & 13.5 & 39 & 75.0 & 6 & 11.5 & 53 & 100 & 0.527 \\
\hline & $\geq 2$ years & 3 & 7.9 & 28 & 73.7 & 7 & 18.4 & 38 & 100 & \\
\hline & Total & 10 & 11.1 & 67 & 74.4 & 13 & 14.4 & 90 & 100 & \\
\hline \multirow[t]{5}{*}{7} & BMI Changes & & & & & & & & & \\
\hline & Decreased & 5 & 10.6 & 35 & 74.5 & 7 & 14.9 & 47 & 100 & 0.918 \\
\hline & Unchanged & 0 & 0.0 & 3 & 75.0 & 1 & 25.0 & 4 & 100 & \\
\hline & Increased & 5 & 12.8 & 29 & 74.4 & 5 & 12.8 & 39 & 100 & \\
\hline & Total & 10 & 11.1 & 67 & 74.4 & 13 & 14.4 & 90 & 100 & \\
\hline \multirow[t]{4}{*}{8} & Diabetic comorbidity & & & & & & & & & \\
\hline & Yes & 6 & 25 & 16 & 66.7 & 2 & 8.3 & 24 & 100 & 0.043 \\
\hline & No & 4 & 6.1 & 51 & 77.3 & 11 & 16.7 & 66 & 100 & \\
\hline & Total & 10 & 11.1 & 67 & 74.4 & 13 & 14.4 & 90 & 100 & \\
\hline
\end{tabular}




\begin{tabular}{|c|c|c|c|c|c|c|c|c|c|c|}
\hline \multirow{2}{*}{\multicolumn{2}{|c|}{ Variables }} & \multicolumn{6}{|c|}{ SGA Score Changes } & \multicolumn{2}{|c|}{ Total } & \multirow[t]{2}{*}{ p-value* } \\
\hline & & \multicolumn{2}{|c|}{ Decreased } & \multicolumn{2}{|c|}{ Unchanged } & \multicolumn{2}{|c|}{ Increased } & & & \\
\hline \multirow[t]{4}{*}{9} & Adequacy of $\mathrm{HD}(\mathrm{Kt} / \mathrm{V})$ & & & & & & & & & \\
\hline & $<1.8$ & 1 & 4.8 & 18 & 85.7 & 2 & 9.5 & 21 & 100 & 0.484 \\
\hline & $\geq 1.8$ & 8 & 12.1 & 47 & 71.2 & 11 & 16.7 & 67 & 100 & \\
\hline & Total & 9 & 10.3 & 65 & 74.7 & 13 & 14.9 & 87 & 100 & \\
\hline
\end{tabular}

\section{Discussion}

Nutritional status characteristics of patients were majority tend to decrease even though SGA score has not been changed yet. It could be shown in unchanged SGA score group, it was $74.5 \%$ of patients experienced decreasing of BMI, and in increased SGA score group (worsening), it was $14.9 \%$ of patients experienced decreasing of BMl. Related to the length of the HD period, it tended to the longer the period of HD the more likely to have to decrease on BMI. It was found $73.7 \%$ of patients with HD period $\geq 2$ years had no improvement of SGA score and higher number patients with increased SGA score (worsening) in HD period $\geq 2$ years group than in $<2$ years group (18.4\% vs. $11.5 \%$ ).

It could be considered that PEW compromising middle-term survival is found in $\sim 25 \%$ of maintenance dialysis patients (Heng and Cano, 2009). PEW was a consequent for HD patients either was caused deteriorating nutrition intake (loss of appetite, anorexia, or protein restriction before HD initials), increasing of nutritional needs (were caused increasing REE (Resting Energy Expenditure) related to inflammation and severe hyperparathyroidism) or loss of nutrients during dialysis. Amino acid and protein losses during the dialysis session, together with low nutrient intake, promote low nutrient availability for muscle synthesis (Lofberg E, 2000 in Carrero, 2013). In dialysis patients, PEW at baseline assessed with SGA was associated with 2-fold increased mortality risk in 7 years of follow-up (Mutsert et al., 2009).

The SGA has been found to be reliable and valid for assessing PEW in HD patients. A single SGA assessment has been shown to be associated with morbidity, hospitalization, and mortality in several clinical studies. Therefore, since 2000 the National Kidney Foundation Kidney Disease/Dialysis Outcomes and Quality Initiative (NKF K/DOQI) has recommended the use of the SGA for assessing the nutritional status of dialysis patients. SGA may validly distinguish different degrees of PEW associated with increasing risks of mortality and recommended shorten interval on monitoring of unstable and malnutrition patients (Mutsert et al., 2009).

Severe PEW in HD patients was very difficult to overcome. Provision of nutritional supplements (high energy emulsions, LCT (Long Chain Triglyceride) with vitamins and minerals) in hemodialysis patients with high SGA scores (poor) found there was no change in $\mathrm{BMI}$ or change in SGA score (Chan, et al., 2014). Severe malnutrition requiring nutritional intervention can be diagnosed by a decrease in $\mathrm{BMI}<20$, a body weight loss $>10 \%$ 
within six months, serum albumin $<35 \mathrm{~g} / \mathrm{l}$ and transthyretin $<300 \mathrm{mg} / \mathrm{l}$ (Heng and Cano, 2010).

The presence of diabetic comorbidity factor was a risk factor for the cause of death in hemodialysis patients. The cumulative survival of the poor $\mathrm{A} 1 \mathrm{C}$ group during the survey was significantly lower than that of the fair and good A1C groups $(p=0.041)$. In diabetic CKD patients on regular hemodialysis, poor glycemic control was an independent predictor of prognosis (Oomichi et al., 2006). Ali et al. (2017) found a poor quality of life on $56.7 \%$ of HD patients with diabetic comorbidity $(p=0.0001)$.

In this study, there was a significant association between diabetic comorbidity and SGA score changes $(p=0.043)$, but it seemed negative correlations. We found there was a 2 - fold proportion of patients with no diabetic comorbidity in increased SGA score group (worsening) compared with proportion of patients with diabetic comorbidity $(16.7 \%$ vs. $8 \%$ ). Similarly, there was a $4-$ fold proportion of patients with diabetic comorbidity in decreased SGA score group (improved) compared with the proportion of patients with no diabetic comorbidity ( $25 \%$ vs. $6.1 \%$ ). This phenomenon was likely influenced by other variables that were not studied in this study such as nutrient intake factor influenced to nutritional status and blood glucose or HbA1c factor described glycemic control of Diabetes. Even in diabetic CKD patients undergoing regular hemodialysis, good glycemic control is an independent predictor of prognosis even after adjustment for known classical factors (Oomichi et al., 2006).

Another phenomenon when viewed mean distribution of age, there was a younger tendency in increased SGA score group (worsening) than in decreased SGA score group (48.8 \pm 15.4 vs. $55.9 \pm 10.4$ years); meanwhile $64.4 \%$ of all patients were maintenance HD patients with HD period $<2$ years. Patients might be anorectic during the weeks or months preceding the start of dialysis, particularly if they were under-managed. Patients might not want to change their whole behavior, including food habits (Locatelli et al. 2002). This phenomenon will be more revealed when the data of nutrient intake was available.

Also, this phenomenon also might be the impact of increased access to CKD treatment stage 5 conducted by the government through universal coverage (BPJS). As in Canada (2008), there were 5431 new patients diagnosed with CKD increased 20\% from 1999, and $76 \%-78 \%$ of them treated HD. Public response was quite good with early treatment so that an increase in the prevalence of CKD per year decline from 4.5\% (for HD 6.1\%) in 2000 to $-1.4 \%$ (for HD -2.3\%) in 2008 (Fortin, C. M. et al., 2010). This was also an indication of the increasing prevalence of CKD stage 5 at a younger age with poor SGA condition. Efforts to improve the nutritional status during the early days of hemodialysis was a potential program to maintain the survival of younger patients.

Based on the mean of the adequacy of $\mathrm{HD}(\mathrm{Kt} / \mathrm{V}), 21$ patients (23.9\%) had inadequate $\mathrm{HD}(\mathrm{Kt} / \mathrm{V}<1.8)$. The data showed a higher number of patients with decreased SGA score (improve) inadequate HD group compared with the number of patients in the inadequate HD group $(12.1 \%$ vs. $4.8 \%$. This seemed consistent with studies that prove the adequacy of hemodialysis affected the nutritional status of patients. But we found there was still a higher proportion of patients with increased SGA score (worsening) inadequate HD group compared with the proportion of patients in the inadequate HD group $(16.7 \%$ vs. 
9.5\%). This study took only eight sessions of HD data for $\mathrm{Kt} / \mathrm{V}$ in the last observation. It might be not enough to describe all adequacy HD process to influence SGA score. When adequacy targets were met in hemodialyzed patients, survival was mainly dependent on age and nutritional status (Combe et al., 2001). Criteria of adequacy were predictors of mortality and morbidity, both on CAPD and HD, whereas normalized protein catabolic rate and subjective global assessment of nutritional status were not (Maiorca et al., 1995).

Prior studies using the ADAT (Appetite and Diet Assessment Tool) have demonstrated an association between increasing appetite assessment scores and increasing protein and energy intake in adequate HD patients. Adequate dialysis (at present a $\mathrm{Kt} / \mathrm{V}>1.2$ for HD) should be provided. Whether a higher $\mathrm{Kt} / \mathrm{V}$ could improve nutritional status was not established at present (Locatelli et al., 2002). Good general and nutritional condition were some of the clinical criteria of adequate dialysis (N.K. Man et al., 1995). Urea reduction was predictor factor for influencing patient's appetite. In this study, $76 \%$ of patients were on adequate HD but the proportion of increased SGA score (worsening) still higher than inadequate HD group. It seemed that the process of improving SGA score was slower than the process of the adequacy of HD. Another reason was adequacy of dialysis had focused on the removal of organic compounds such as urea. Hemodialysis mainly works on the principle of diffusion in which the substances with a lower concentration in dialysate than in blood to be removed by dialysis. This leads to depletion of many important inorganic substances such as phosphor and zinc which contributed to energy metabolism. Poor nutrition intake would be worsening this condition. Fortunately, the nutrition intake data was not available in this study. Again, there were some limitations for this study to measure appetite led to protein intake that could be correlated with the adequacy of HD.

\section{Conclusions and Recommendations}

The increased prevalence of HD patients with increased SGA score (worsening) especially in younger patients and the period of HD under two years was a sign for the requirement of the better monitoring program and nutrition improvement. Larger sample size and longer observation period and observation of variables such as nutritional intake, periodical measurement of adequate $\mathrm{Kt} / \mathrm{V}$, measurement of appetite appraisal score, blood glucose examination or $\mathrm{HbA1C}$ related to glycemic control in diabetic comorbidity were needed to obtain a more significant change in nutritional status and the dominant influenced variables. For further studies, it was needed to get a deeper correlation and regression to see the dominant determinant variables in nutritional status changes which impact on mortality and quality of life of patients. Monitoring program and nutrition improvement of HD patients had a chance for survival of younger patients.

\section{Acknowledgments}

Especially thank for RSIJ Cempaka Putih Hospital primarily for Hemodialysis Unit and Nutrition Department. 


\section{Conflict of Interest}

The authors declare that they have no conflict of interests.

\section{References}

[1] Zhang, Q., \& Rothenbacher, D. (2008). Prevalence of Chronic Kidney Disease in Population-Based Studies: Systematic review, 13. https://doi.org/10.1186/1471-2458-8-117

[2] Fortin, C. M., Williams, B., Ivis, F., Na, Y., \& Hall, N. (2010). Canadian Institute for Health Information, Treatment of End-Stage Organ Failure in Canada, 1999 to 2008-CORR 2010 Annual Report. Retrieved from https://www.kidney.ca/document.doc?id=855,

[3] Levey, A.S, Coresh J, Chronic Kidney Disease, www.thelancet.com Vol 379 January 14, 2012,//www. ncbi.nlm.nih.gov/pubmed/21212690

[4] Indonesian Renal Registry (2012) '5th Report Of Indonesian Renal Registry 2012', Program Indonesia Renal Registry, pp. 12-13. http://www.pernefri-inasn.org/Laporan/5th Annual Report Of IRR 2012.pdf.

[5] Atkins, R. C. (2005) 'The Epidemiology of Chronic Kidney Disease', Kidney International, 67, pp. S14-S18. doi: 10.1111/j.1523-1755.2005.09403.x., http://linkinghub.elsevier.com/retrieve/pii/S0085253815507801

[6] Barker, Lisa A., et al., Hospital Malnutrition: Prevalence, Identification, and Impact on Patients and the Healthcare System, Int. J. Environ. Res. Public Health 2011, 8, 514-527; doi:10.3390/ijerph8020514 OPEN ISSN 1660-4601, www.mdpi.com/journal/ijerph,

[7] Heng, A. E., and Cano, N. J. M. (2010) 'Nutritional Problems in Adult Patients with Stage 5 Chronic Kidney Disease on Dialysis (Both Haemodialysis and Peritoneal Dialysis)', NDT Plus, 3(2), pp. 109-117. doi: 10.1093/ndtplus/sfp147. http://ckj.oxfordjournals.org/byguest on January 2, 2017

[8] Locatelli, F. (2002) 'Nutritional Status in Dialysis Patients: A European Consensus,' Nephrology Dialysis Transplantation, 17(4), pp. 563-572. doi: 10.1093/ndt/17.4.563. http://ndt.oxfordjournals.org/cgi/content/ long/17/4/563 https://remote-lib.ui.ac.id:6127/ndt/article-lookup/doi/10.1093/ndt/17.4.563

[9] Rocco, M. et al. (2015) 'KDOQI Clinical Practice Guideline for Hemodialysis Adequacy: 2015 Update', American Journal of Kidney Diseases, 66(5), pp. 884-930. doi: 10.1053/j.ajkd.2015.07.015 https:// remote-lib.ui.ac.id:6066/docview/216536342/fulltextPDF/84997271B25E4C7APQ/1?accountid=17242,

[10] Man, N.K., Zingraff J, Jungers, P. (1995) Long-term Hemodialysis. Springer-Science+Business Media, B.V. https://link.springer.com/book/10.1007?978-94-011-0027-4

[11] Rocco, M. V. et al. (2004) 'The Effect Of Dialysis Dose and Membrane Flux on Nutritional Parameters In Hemodialysis Patients: Results of the HEMO Study', Kidney International, 65(6), pp. 2321-2334. doi: 10.1111/j.1523-1755.2004.00647.x. http://www.sciencedirect.com/science/article/pii/ S0085253815499788

[12] Mutsert, D. et al. (2009) 'Subjective Global Assessment of Nutritional Status is Strongly Associated with Mortality in Chronic Dialysis Patients 1 - 4', American Journal of Clinical Nutrition, pp. 787-793. doi: 10.3945/ajcn.2008.26970.Am, http://ajcn.nutrition.org/content/89/3/787.full.pdf+html

[13] Oomichi, T. et al. (2006) 'Impact of Glycemic Control on Survival of Diabetic Patients on Chronic Regular Hemodialysis: A 7-Year Observational Study', Diabetes Care, 29(7), pp. 1496-1500. doi: 10.2337/dc051887, http://www.indianjnephrol.org/article.asp?issn=0971-4065; year=2017; volume=27;issue=4;spage= 277; epage=2;

[14] Maiorca, R. et al. (1995) 'Predictive Value of Dialysis Adequacy and Nutritional Indices for Mortality and Morbidity in CAPD and HD Patients. A Longitudinal Study.', Nephrology, dialysis, transplantation: official publication of the European Dialysis and Transplant Association - European Renal Association, 10(12), pp. 2295-2305. https://academic.oup.com/ndt/article-abstract/10/12/2295/1804807 